\title{
Instrumento de mensuração de qualidade de materiais didáticos para a educação à distância
}

\section{Instrument to measure the quality of didactic material for long distance education}

\author{
Silvio Paula Ribeiro \\ Universidade Federal de Mato Grosso do Sul, UFMS (Brasil) \\ Viviane da Costa Freitag \\ Miguel Afonso Sellitto \\ Universidade do Vale do Rio dos Sinos, UNISINOS (Brasil)
}

\section{Resumo}

O propósito desse estudo é apresentar um modelo de mensuração da qualidade de materiais didáticos para educação à distância $(\mathrm{EaD})$. $\mathrm{O}$ método de pesquisa utilizado foi a modelagem de apoio multicritério à decisão, por meio do Analytic Hierarchy Process (AHP), e utilizou o software Assistat 7,0 Beta para obter as matrizes hierárquicas e seus respectivos Índices de Consistência. A revisão literária identificou os materiais didáticos comumente utilizados pela EaD. Na sequência, especialistas avaliaram e adaptaram o modelo, para apresentar aos atores do estudo. Os resultados são: documentos orientativos de qualidade na EaD que avaliam os materiais didáticos não elegem um grau de importância aos elementos, apenas os elencam e fornecem linhas gerais de padrões de qualidade; o AHP hierarquizou os materiais didáticos, por grau de importância; o livro texto possui o maior percentual, seguido de vídeo aulas. Esses são os itens que devem absorver maior atenção dos gestores em termos de qualidade, seguidos pelo chat e o rádio. Ao considerar todas as sub-categorias avaliadas para cada material didático, observa-se que o livro texto é o material que prioritariamente requer atenção, ao que se refere à abrangência de conteúdo, seguida de conteúdos livre de erros, viés conceituais ou de abordagem e por fim, a qualidade visual ou gráfica. A sub-categoria de qualidade, que derivam das vídeo aulas prioritariamente são: material livre de erros, viés conceitual ou de abordagem. Essas categorias foram delineadas em consonância com dois padrões de referência para a qualidade de materiais didáticos: AFT (2000) e MEC (2007).

Palavras-chave: EaD; avaliação de qualidade; materiais didáticos; AHP.

\section{Abstract}

The objective of this study was to present a model to measure the quality of didactic material used for distance learning (EaD). The research method used was data modeling 
to support multi-criteria decision-making, through Analytic Hierarchy Process (AHP), and it used the software Assistant 7,0 Beta in order to obtain hierarchical matrices and their respective Consistency Index. The literary review identified the didactic material commonly used for distance learning. Following, specialists assessed and adapted the model to introduce it to the actors in the study. The results were that guiding quality in distance learning (EaD) documents that assess didactic material did not elect a degree of importance to the elements, they just listed and offered general guidelines to the quality standard; the AHP ranked the didactic materials according to their importance, the textbook had the highest percentage, followed by the video lessons. These items should absorb more attention from managers in terms of quality, followed by chat and radio. Considering all subcategories assessed by each didactic material, it was possible to observe that the text book is the one that requires more attention in terms of priority, in relation to the scope of its content, then the content must be error-free, without conceptual or approach bias , and finally with good graphic and visual quality. The quality subcategory that derives from video lessons are error-free material and without conceptual or approach bias. These categories were outlined in accordance with two reference standards for quality and didactic materials: AFT (2000) e MEC (2007).

Keywords: EaD; quality assessment; didactic materials; AHP.

A inovação tecnológica tem influenciado todos os setores sociais, motivada pela geração de oportunidade, principalmente em situações onde favorecem a mobilidade das pessoas, entre a compra, venda, entrega de produtos e serviços. Assim, como em todos os segmentos da economia, a educação vem acompanhando as mudanças geradas pelo avanço tecnológico, por meio de sistemas que registram e integram questões acadêmicas em termos de acompanhamento de currículos, históricos, recepção de materiais por meio dos portais, acesso à base de dados, gravação de vídeo aulas, bibliotecas virtuais, entre tantas funcionalidades. Enfim, a tecnologia proporciona uma série de oportunidades de diversas naturezas noâmbito educacional, ressaltando que outra opção concebida pelo avanço tecnológico na educação ocorre pela oferta de cursos em plataformas virtuais, denominadas Educação à Distância (EaD). Nessa esteira, Fratucci (2015) afirma que a EaD, encontra-se disseminada em todas as partes do mundo, devido à necessidade de atender a crescente parcela da população que busca a formação inicial ou continuada, a fim de adquirir condições de competir no mercado de trabalho.

Durante a realização do I Symposium Iberoamericano de Rectores de Universidades Abiertas y a Distancia, realizado na Universidad Nacional de Educación a Distancia (UNED) da Espanha, realizado em Madrid, no período de 5 a 10 de outubro de 1980, foi acordado que para promover uma maior expansão da $\mathrm{EaD}$, na América Latina era conveniente criar um mecanismo de informação, coordenação, pesquisa e cooperação (Aretio, 2016). Portanto, o tema a quase 40 anos já era motivo de preocupação no meio acadêmico e mostrava-se relevante.

Por conta da alta demanda relacionada a qualificação das pessoas no Brasil, algumas instituições de ensino (IE) procuram atender a sociedade, oferecendo 
serviços de EaD. Nessa corrente pode-se afirmar que embora, alguns cursos de $\mathrm{EaD}$ façam uso de modelos convencionais de transmissão que dificultam o estabelecimento de inter-relações entre emissor e receptor, processo e produto e apresente altos índices de desistência, existe um mercado que necessita dessa formação e por razões diversas não tem acesso ao ensino presencial, seja pela: distância física de centros de formação, impossibilidade de estudar em centros de referência de área, ou ainda a falta de recursos financeiros que possam custear essa atividade.

Portanto, é nesse cenário que se cria a necessidade de formação de um corpo profissional formado por docentes, monitores e técnicos capacitados para o atendimento desses estudantes, que sejam competentes ao que se refere à criação de materiais didáticos de qualidade. Esses profissionais devem trabalhar com as peculiaridades tecnológicas, dialógicas, técnicas e de qualidade, por conta da importância econômica e social que permeia a EaD. Em relação a essa constatação Gomes (2013) afirma que os processos de crescimento, expansão, diversificação, especialização e diferenciação dos sistemas de educação superior, associados à generalização da informática e das telecomunicações - estimuladas pela tendência na modernização produtiva e a globalização dos mercados deram espaço à emergência de novos cenários e modalidades de ensino.

Salienta-se que essa investigação, possui interesse particular na qualidade do material didático gerado pela $\mathrm{EaD}$, no âmbito dos cursos de graduação, uma vez que investigações sobre a qualidade na $\mathrm{EaD}$ envolveram questões sobre: a qualidade no processo de aprendizado de forma geral, Rué et al. (2009); os aspectos teóricos da avaliação da qualidade na EaD Peeva (2010); a qualidade nos serviços dos ambientes virtuais de aprendizagem, Argüelles, Callejo e Farrero (2013); a qualidade no processo de aprendizado, Vagarinho e Lamas-Nistal (2013), e que não foi encontrado investigação específica que aborde a qualidade dos materiais didáticos utilizados na EaD. Esse material de forma genérica inclui no mínimo um livro texto, utilizado como referência básica principal, vídeo aulas, chat e rádio. Esse estudo pretende gerar uma escala de mensuração da qualidade de materiais didáticos para a EaD. Dessa forma, a questão principal é: como gerar uma escala de mensuração da qualidade de materiais didáticos para a Educação à Distância? A principal contribuição desse estudo trata-se da apresentação de um modelo de mensuração da qualidade de materiais didáticos para a EaD.

O método de pesquisa utiliza a modelagem de apoio multicritério à Decisão, por meio do Processo de Análise Hierárquica (AHP), o qual a partir do termo de topo derivou os materiais didáticos utilizados pela EaD: livro texto, vídeo aulas, chat e rádio. Ao fazer a revisão da literatura foi possível distribuir entre as categorias, os materiais didáticos. Na sequência, um grupo focado de especialistas adaptaram o modelo à realidade da EaD. Para enfim, a aplicação ocorrer em agosto de 2016 junto à coordenadores que atuam na $\mathrm{EaD}$ no Brasil. 


\section{DESENVOLVIMENTO DA EDUCAÇÃO A DISTÂNCIA}

O crescimento da educação na modalidade EaD é impulsionado pela possibilidade de redução de custos, tanto para alunos, quanto para instituições, pela minimização do problema de deslocamento do aluno até a unidade de ensino, e a flexibilidade do horário no processo de ensino e aprendizagem. Um dos fatores que confere sucesso ao modelo implica na maturidade dos acadêmicos no sentido de organização e respeito ao cronograma (Downes, 2009; Tondim, 2009). Nesse sentido, Mugnol (2009, p. 340) afirma que "a metodologia aplicada na EaD prima pela conscientização dos alunos sobre o seu papel no resultado das atividades acadêmicas para o seu aprendizado". Vale ressaltar que nessa modalidade o docente também tem uma participação importantíssima, pela oportunidade de preparar o material, as vídeos aulas, participar do chat e propor o sistema de avaliação.

Os resultados de Ramírez (2016), por sua vez, demonstram que diversos fatores, com exceção da ansiedade pelo uso do computador apresentaram-se significativamente correlacionados com a satisfação estudantil. E que fatores como a flexibilidade, atitude docente, auto eficiência do estudante no uso da internet e percepção da interação satisfazem quantidade relevante dos estudantes da modalidade $\mathrm{EaD}$ entrevistados.

A Associação Brasileira de Educação a Distância (ABED) aponta para o crescimento dos cursos superiores ofertados a distância em $2.588,5 \%$, no período de 2003 a 2014, em contrapartida as graduações superiores presenciais tiveram no mesmo período um crescimento de apenas 66,9\%, (ABED, 2016). Na Espanha a Universidad Nacional de Educación a Distancia (UNED) conta atualmente com 260.00o estudantes, 27 cursos de graduação, 49 de mestrado, 610 Programas de Treinamento Continuado, mais de 8.600 professores. Esta universidade foi a responsável pelo nascimento da Asociación Iberoamericana de Educación Superior a Distancia (AIESAD) que é o organismo de coordenação e cooperação entre as instituições Ibero-americanas interessadas na educação à distância (García Aretio, 2016). Esses números ressaltam o escopo de atuação da EaD.

Vale ressaltar que a educação à distância ainda merece muita atenção e que os aspectos gerais de todo o sistema de ensino deve ser analisado para o desenvolvimento dessa modalidade e para continuar atendendo aos diversos usuários é necessário também procurar fazer uma avaliação do serviço em si, com o propósito de melhorar as condições de ensino (Udo, Bagchi e Kirs, 2011).

Com o propósito de investigar as linhas e as tendências da educação a distância na América Latina, Perez e Aretio (2016) estudaram 184 teses de doutorado, nessa temática, oriundas de diversos programas de pós graduação de vários países. Do total, mais de $60 \%$ são de universidades brasileiras, a pesquisa dividiu as teses em três áreas: nível macro, os sistemas de educação a distância e suas teorias; nível médio, organização e tecnologia; nível micro, ensino e aprendizagem na educação 
a distância. Destas, destaca-se que o desenho instrucional corresponde a apenas $1,63 \%$ das teses, e é neste item que foi enquadrado o material didático.

O estudo ainda considera que a dispersão de temas não foi significativa e que existem áreas dentro da educação a distância que merecem ser investigadas, tais como: transferência de conhecimento; acesso, a equidade e ética. (Perez e Aretio, 2016).

Entre as temáticas da educação à distância que carecem de investigação, encontrase a tecnologia, que é "essencialmente uma atividade prática, a qual consiste mais em alterar do que em compreender o mundo. Onde a ciência persegue a verdade, a tecnologia prega a eficiência", (Kneller, 1980, pp. 245-246). Nesse contexto, Valente e Mattar (2007, p. 20) ressaltam que "recentemente, a EaD, passou a utilizar, com maior intensidade, tecnologias de telecomunicação e transmissão de dados, som e imagens que convergem cada vez mais para o computador". Nessa esteira Tondin (2009) afirma que o processo de formação da EaD é composto pela necessidade de educação, pela distância entre os agentes, avanços da tecnologia e pela melhora nos meios de comunicação. Foi o advento das Tecnologias de Informação e Comunicação (TIC) que gerou condições de desenvolvimento de desenho do curso e produção sofisticada, rápida emissão e distribuição de conteúdo, interação com informações, recursos e pessoas (Almeida, 2012; Komarinski, 2015).

O uso de processos de comunicação e tecnologias em rede, desloca a estrutura tradicional e formal para a especificidade de cada aluno, personalizando e individualizando as necessidades pedagógicas do aluno e influindo na concepção e ação do docente (Paese, 2012).

Portanto, a EaD com auxílio de novas tecnologias proporcionou a possibilidade de desenvolvimento do conhecimento, e redução de custos, tanto para o aluno, quanto para a instituição de ensino. Porém, essa nova construção exige das instituições credenciadas treinamento dos seus colaboradores no desenvolvimento de material e conhecimento pedagógico para atender essa nova demanda social. No Brasil apesar desta prática de serviços estar devidamente regulamentada, ainda carece de processo de melhorias. Nessa perspectiva Silva, Melo e Muylder (2015) apontam que os fatores críticos da EaD são: a estrutura do curso, perfil do aluno, capacitação e treinamento dos professores e tutores, suporte ao aluno, modelos e recursos pedagógicos, estratégias de comunicação e interação.

O aspecto legal da educação a distância no Brasil foi estabelecido pela Lei de Diretrizes e Bases da Educação Nacional, Lei 9.394/1996, Decreto 2.494/1998, Decreto 2.561/1998 e Portaria Ministerial 301/1998. Esses aspectos estabeleceram a oferta de cursos nos níveis: fundamental, médio e técnico. E também para o ensino superior e educação profissional em nível tecnológico e a pós-graduação a distância (Tachizawa e Andrade, 2003).

O Ministério da Educação e Cultura (MEC) no documento que constitui Referenciais de Qualidade para Educação Superior à Distância, afirma que esses "devem estar em consonância com o projeto pedagógico do curso, o material didático, 
deve desenvolver habilidades e competências específicas, recorrendo a um conjunto de mídias compatível com a proposta e com o contexto socioeconômico do públicoalvo" (MEC, 2007, p. 13).

Em relação ao estabelecimento dos materiais didáticos criados para a $\mathrm{EaD}$, o (MEC, 2007), os define como: material impresso, vídeos, programas televisivos e radiofônicos, videoconferências, CD-ROM, páginas $W E B$ e objetos de aprendizagem. Esses devem atender a diferentes lógicas de concepção, produção, linguagem, estudo e controle de tempo. Gil (2012) também considera o uso da televisão, rádio, vídeo, e-mail, vídeo conferência, powerpoint, internet, base de dados, vídeo aulas, programas matemáticos/estatísticos/específicos por área, fóruns de discussão online, entre outros artefatos que ampliam a capacidade de ensinar. Nesse sentido, buscou-se métricas de avaliação para os materiais didáticos direcionados para o e-learning.

\section{AVALIAÇÃo DE MATERIAIS DIDÁTICOS PARA A EaD}

A ideia de qualidade data de 1998, quando seis países europeus registraram haver realizado algum tipo de controle de qualidade e dados de 2010 indicam que mais de 200 organizações estão inscritas na (INQAAHE) International Network for Quality Assurance Agencies in Higher Education (Montalvo, Luna y Montenegro 2010).

No estudo de Peeva (2010), a qualidade pode ser utilizada como um dispositivo de medição de todo o sistema, em termos gerenciais pode ser medida como a conformidade mediante certas especificações. A literatura aponta algumas obras voltadas para a avaliação da EaD de uma forma geral.

Quadro 1. Autores, título e objetivo dos estudos sobre qualidade

\begin{tabular}{|l|l|l|}
\hline \multicolumn{1}{|c|}{ AUTORES } & \multicolumn{1}{|c|}{ TÍTULO } & \multicolumn{1}{c|}{ OBJETIVO } \\
\hline Rué et al. (2009) & $\begin{array}{l}\text { Avaliar a qualidade do } \\
\text { aprendizado na educação } \\
\text { superior: um modelo ECAo8 } \\
\text { como base para a análise das } \\
\text { evidências sobre a qualidade da } \\
\text { EaD }\end{array}$ & $\begin{array}{l}\text { Verificar a noção de qualidade } \\
\text { nos interesses dos processos de } \\
\text { ensino e aprendizagem. }\end{array}$ \\
\hline Peeva (2010) & $\begin{array}{l}\text { Aspectos teóricos da avaliação da } \\
\text { qualidade do Ensino Superior. }\end{array}$ & $\begin{array}{l}\text { Fazer uma revisão das fontes, as } \\
\text { quais definem a qualidade na área } \\
\text { de educação, de forma geral. }\end{array}$ \\
\hline $\begin{array}{l}\text { Argüelles, Callejo e } \\
\text { Farrero (2013) }\end{array}$ & $\begin{array}{l}\text { As dimensões da qualidade } \\
\text { dos serviços observadas nos } \\
\text { ambientes virtuais de formação } \\
\text { superior. }\end{array}$ & $\begin{array}{l}\text { Desenvolver um sistema, modelos } \\
\text { e escalas que permitem obter } \\
\text { medidas válidas, confiáveis e } \\
\text { consistentes. }\end{array}$ \\
\hline
\end{tabular}




\begin{tabular}{|l|l|l|}
\hline \multicolumn{1}{|c|}{ AUTORES } & \multicolumn{1}{|c|}{ TÍTULO } & \multicolumn{1}{c|}{ OBJETIVO } \\
\hline $\begin{array}{l}\text { Vagarinho e Lamas- } \\
\text { Nistal (2013) }\end{array}$ & $\begin{array}{l}\text { Evolução da qualidade dos } \\
\text { processos de aprendizagem: uma } \\
\text { proposta com novas dimensões. }\end{array}$ & $\begin{array}{l}\text { Verificar o estado da arte sobre } \\
\text { a qualidade dos processos de } \\
\text { aprendizagem em relação as } \\
\text { novas dimensões do e-learning. }\end{array}$ \\
\hline $\begin{array}{l}\text { Caetano et al. } \\
(2015)\end{array}$ & $\begin{array}{l}\text { Desempenho no ENADE em } \\
\text { Ciências Contábeis: EaD versus } \\
\text { presencial. }\end{array}$ & $\begin{array}{l}\text { Verificar se existe diferença } \\
\text { significativa entre as notas dos } \\
\text { alunos dos cursos de Ciências } \\
\text { Contábeis das modalidades de } \\
\text { EaD e presencial. }\end{array}$ \\
\hline
\end{tabular}

Fonte: Pesquisa bibliográfica (2016).

Diante das referências utilizadas para o desenvolvimento dessa pesquisa observase a preocupação e a importância do assunto, pois trata de educação, considerada uma modalidade de serviço, a qual direta ou indiretamente interfere ou influência nas diversas áreas de conhecimento.

Em estudo relacionado as dimensões da avaliação da qualidade do e-learning, Vagarinho e Lamas-Nistal (2013) consideram que nenhuma entidade engloba os quinze itens referidos como: acreditação, alunos, avaliação, cultura de qualidade, curso, ética, informação, institucional, leis, materiais, pedagogia, professores, recursos, segurança e suporte.

Já em relação a qualidade na modalidade $\mathrm{EaD}$, Caetano et al. (2015) verificaram que as notas dos alunos dos cursos a distância apresentam-se estatisticamente inferiores a dos discentes dos cursos presenciais. Esses resultados sugerem diferenças na qualidade do ensino e a necessidade de acompanhamento do desempenho dos estudantes da modalidade EaD, haja vista a expansão quantitativa que ela vem alcançando no Brasil.

Com preocupação voltada para a avaliação do material didático na modalidade EaD, Teçariol e Ikeshoji, (2016, p. 292) apontam que

O material didático deve ser pensado como um elemento que pela sua própria natureza seja articulado com a tecnologia. Sendo assim, caberá à equipe multidisciplinar responsável pela concepção e produção dos materiais didáticos nas diferentes mídias favorecer e colaborar para o desencadeamento de um sistema de avaliação prévia de todos os materiais, orientações e recursos tecnológicos a serem utilizados em uma disciplina ou curso, com o intuito de realizar sua pré-testagem.

Sobre a qualidade do material Vagarinho e Lamas-Nistal (2013) ao estudarem a evolução da qualidade nos processos de $\mathrm{EaD}$ elencaram os comitês e agências que conferem padrões de qualidade para os mesmos, dentre esses, buscou-se àqueles que desenvolveram padrões para os materiais didáticos, a saber: Open \& Distance Learning Quality Council (ODLQC) e American Federation of Teachers (AFT). 
O Open \& Distance Learning Quality Council (ODLQC) é um conselho que se dedica a cuidar dos padrões de qualidade de educação aberta e a distância, sediado no Reino Unido, atua desde 1968 e passou a trabalhar de forma independente a partir de 1995. O objetivo do Conselho é identificar e melhorar a qualidade do ensino e da formação (ODLQC, 2016).

A American Federation of Teachers (AFT) foi fundada em 1916 e representa hoje 1,6 milhões de professores em mais de 3.00o filiais locais em todo os Estados Unidos, essa Federação é um órgão de classe e emite um guia das melhores práticas para a EaD.

Alguns temas fazem parte da avaliação da ODLQC, entre esses: verificar se os recursos fornecidos são adequados às necessidades, conhecimento e experiência de um grupo declarado de alunos; que o prestador tome todas as medidas razoáveis para garantir que os materiais do curso sejam eficazes e não contenham erros significativos de fato, ou de informações, conceitos ou abordagens enganosas ou desatualizadas; se os materiais do curso são projetados para uma oportunidade específica e adequada para o apoio ao aluno; se os materiais são estruturados para facilitar e desenvolver o estudo e habilidades individuais do aluno; e por último o quesito resultados confere se os métodos e materiais de apoio oferecidos pelo curso são suficientes para alcançar os resultados pretendidos (ODLQC, 2016).

A AFT se pronuncia quanto à abrangência e profundidade do material disponibilizado para o e-learning, que deve ser o suficiente para cobrir todo um curso caso fosse presencial e que além do acesso, o aluno detenha a possibilidade de analisar o material de forma crítica. A AFT não faz menção sobre quais são os materiais, bem como padrões que definam sua qualidade.

No Brasil, a qualidade da EaD, é consubstanciada pelo documento emitido pelo MEC/SEED (2007) denominado Referenciais de Qualidade para Educação Superior a Distância. Sua primeira versão foi publicada no ano de 2003, depois revisada em 2007 em consonância com a LDB e demais resoluções e portarias que a atualizam esse documento. Portanto, pode-se considerar que os referenciais de qualidade para projetos de cursos na modalidade a distância necessitam trabalhar com os aspectos pedagógicos, recursos humanos e infraestrutura, e dentre esses aspectos, os materiais didáticos são avaliados (MEC, 2007).

Quadro 2. Avaliação de materiais didáticos para a EAD

\begin{tabular}{|l|l|l|l|}
\hline Documento/data & $\begin{array}{l}\text { Referenciais sobre } \\
\text { EaD }\end{array}$ & \multicolumn{1}{|c|}{ Material } & \multicolumn{1}{c|}{ Avaliação } \\
\hline AFT (2000) & $\begin{array}{l}\text { Distance Education: } \\
\text { Guidelines for Good } \\
\text { Practice. }\end{array}$ & $\begin{array}{l}\text { Os alunos precisam } \\
\text { de ter acesso a um } \\
\text { amplo espectro de } \\
\text { materiais de pesquisa } \\
\text { e aprender como } \\
\text { avaliar tal material } \\
\text { criticamente. }\end{array}$ \\
\hline
\end{tabular}




\begin{tabular}{|c|c|c|c|}
\hline Documento/data & $\begin{array}{c}\text { Referenciais sobre } \\
\text { EaD }\end{array}$ & Material & Avaliação \\
\hline MEC (2007) & $\begin{array}{l}\text { Referenciais de } \\
\text { Qualidade para } \\
\text { Educação Superior à } \\
\text { Distância. }\end{array}$ & $\begin{array}{l}\text { Material impresso, } \\
\text { vídeos, programas } \\
\text { televisivos e } \\
\text { radiofônicos, } \\
\text { videoconferências, } \\
\text { CD-Rom, páginas } \\
W E B, \text { objetos de } \\
\text { aprendizagem. }\end{array}$ & $\begin{array}{l}\text { Abrangência } \\
\text { e organização } \\
\text { do conteúdo, } \\
\text { estruturação } \\
\text { de linguagem } \\
\text { dialógica, nível de } \\
\text { conhecimento prévio } \\
\text { exigido para aquele } \\
\text { conteúdo, indicação } \\
\text { de bibliografia } \\
\text { ou de materiais } \\
\text { complementares. }\end{array}$ \\
\hline ODLQC (2016) & $\begin{array}{l}\text { Standards in Open } \\
\text { and Distance } \\
\text { Learning. }\end{array}$ & $\begin{array}{l}\text { Não especifica o tipo } \\
\text { do material. }\end{array}$ & $\begin{array}{l}\text { Adequação ao nível } \\
\text { de experiência dos } \\
\text { alunos, material } \\
\text { livre de erros, livre } \\
\text { de viés conceitual } \\
\text { ou de abordagem, } \\
\text { atualizado. }\end{array}$ \\
\hline
\end{tabular}

Fonte: Pesquisa bibliográfica (2016).

O quadro 02, apresenta uma compilação sobre os padrões de qualidade para os materiais didáticos para a EaD. A ODLQC detalhou a forma de avaliação, já o MEC, além de detalhar a forma de mensuração, especificou os tipos de materiais a serem avaliados em termos de qualidade.

\section{PROCEDIMENTOS METODOLÓGICO}

O estudo iniciou-se pela busca nas bases de dados Ebsco host e Capes com os termos: educação à distância, qualidade na $\mathrm{EaD}$, materiais didáticos para a $\mathrm{EaD}$ e mensuração dos materiais didáticos. A partir das leituras preliminares foram separados os estudos e normativos que tratam da EaD e mais especificamente sobre padrões de qualidade e materiais didáticos.

A pesquisa faz uso do método de apoio ou auxílio multicritério à decisão: Analytic Hierarchy Process (AHP), onde os especialistas priorizam constructos e dimensões da estrutura referencial. O método, por sua vez, é ancorado pela escola americana que trabalha com julgamentos diretos e considera a reciprocidade.

Os múltiplos objetivos em problemas de decisão foi considerado em 1944, quando do surgimento da teoria da utilidade de Von Neumann e Morgenstern, esses demonstraram que qualquer consequência em uma decisão é mais naturalmente 
descrita, por meio de um vetor que representa valores em mais de uma dimensão (objetivo) (Almeida, 2013).

Para Gomes, González, Araya e Carignado (2004), o AHP é um método que colabora e justifica uma escolha, ou decisão, a partir da determinação de critérios e seus pesos extraídos das preferências dos decisores. Esse método foi desenvolvido na década de 70 pelo Professor Thomas Saaty, baseado em conceitos de matemática e psicologia. O AHP fornece um procedimento compreensivo e racional para modelar um problema de decisão, representando e quantificando as variáveis envolvidas em uma hierarquia de critérios ponderados por preferências (pesos). $\mathrm{O}$ resultado é um modelo que permite analisar várias alternativas e as comparar rapidamente. A hierarquia de critérios e pesos do AHP é definida pelos tomadores de decisão à medida que se constrói o modelo. Os critérios são comparados entre si, dois a dois, o que introduz um componente subjetivo no modelo.

Oliveira e Martins (2015) ressaltam que na fase de julgamentos paritários, o tomador de decisão segue axiomas, no caso desses não serem aplicados, isso significa que as alternativas não são comparáveis.

Quadro 3. Axiomas AHP

\begin{tabular}{|c|l|l|}
\hline N. & \multicolumn{1}{|c|}{ Axioma } & \multicolumn{1}{c|}{ Aplicação } \\
\hline 1 & $\begin{array}{l}\text { Comparação } \\
\text { Recíproca }\end{array}$ & $\begin{array}{l}\text { O decisor deve ser capaz de comparar e impor suas preferências, a } \\
\text { inexistência desse, indica que a pergunta não é clara, ou não está } \\
\text { correta. }\end{array}$ \\
\hline 2 & Homogeneidade & $\begin{array}{l}\text { As preferências são representadas pelo princípio em uma escala } \\
\text { limitada cujo limite superior é 9. }\end{array}$ \\
\hline 3 & Independência & $\begin{array}{l}\text { Os critérios declarados como preferências devem ser independentes } \\
\text { das propriedades das alternativas. }\end{array}$ \\
\hline 4 & Expectativa & $\begin{array}{l}\text { Espera-se que a proposta estruturada esteja completa com todas as } \\
\text { alternativas avaliáveis para uma tomada de decisão. }\end{array}$ \\
\hline
\end{tabular}

Fonte: Adaptado de Oliveira e Martins (2015).

A partir das definições derivadas do termo de topo, para as categorias e níveis inferiores foram elencados os padrões de qualidade a serem observados para cada material didático, assim foram dispostos os itens que atendem ao axioma de comparação recíproca. Para atender o axioma de homogeneidade, a escala utilizada para a construção de matrizes de preferências (matrizes quadradas recíprocas positivas), seguindo a escala [1-9] foi a proposta por Saaty (2008). 
Tabela 1. Escala de Importância de Saaty (2008)

\begin{tabular}{|l|c|l|c|}
\hline \multicolumn{1}{|c|}{ Igual } & 1 & \multicolumn{1}{c|}{ Igual } & 1 \\
\hline Um pouco mais importante & 3 & Um pouco menos importante & $1 / 3$ \\
\hline Mais importante & 5 & Menos importante & $1 / 5$ \\
\hline Muito mais importante & 7 & Muito menos importante & $1 / 7$ \\
\hline Absolutamente mais importante & 9 & Absolutamente menos importante & $1 / 9$ \\
\hline
\end{tabular}

Fonte: Saaty (2008).

Essa escala permite a comparação pareada entre os elementos. Os critérios atendem o axioma de independência das propriedades das alternativas, e acredita-se que o axioma expectativa tenha sido atendido considerando a realização da pesquisa bibliográfica, contudo, também se trata de uma limitação do estudo.

O processo de hierarquia analítica para a tomada de decisão por prioridades precisa ser decomposto em etapas (Saaty, 2008).

Quadro 4. Decomposição do processo de hierarquia

\begin{tabular}{|l|l|l|}
\hline No & \multicolumn{1}{|c|}{ Etapas do Processo } & \multicolumn{1}{c|}{ Etapa do Estudo } \\
\hline 1 & $\begin{array}{l}\text { Definir o problema e determinar o tipo de } \\
\text { conhecimento procurado. }\end{array}$ & $\begin{array}{l}\text { Gerar uma escala de mensuração da } \\
\text { qualidade de materiais didáticos da EaD. }\end{array}$ \\
\hline 2 & $\begin{array}{l}\text { Estruturar a hierarquia de decisão com o o } \\
\text { objetivo de topo da decisão, em seguida, } \\
\text { definir os objetivos de uma perspectiva } \\
\text { ampla, por meio dos níveis intermédios. }\end{array}$ & $\begin{array}{l}\text { Termo de Topo: Avaliação de Materiais } \\
\text { didáticos no ensino a distância. } \\
\text { Nível Intermediário: definição dos } \\
\text { materiais didáticos. }\end{array}$ \\
\hline 3 & $\begin{array}{l}\text { Construir um conjunto de matrizes de } \\
\text { comparação par a par. Cada elemento em } \\
\text { um nível superior é usado para comparar } \\
\text { os elementos no nível imediatamente } \\
\text { abaixo com relação a ele. }\end{array}$ & $\begin{array}{l}\text { Matriz 4X4 deriva do nível intermediário } \\
\text { para o nível imediatamente inferior. O } \\
\text { nível intermediário é composto pelos } \\
\text { materiais didáticos: livro texto, vídeo } \\
\text { aulas, chat e rádio, e o nível inferior foi } \\
\text { extraído dos documentos que elencam } \\
\text { padrões de qualidade para materiais } \\
\text { didáticos na EaD. }\end{array}$ \\
\hline
\end{tabular}

Fonte: Pesquisa bibliográfica (2016).

A etapa um foi apresentada na introdução desse estudo, na sequência (etapa dois) foi definida a partir do referencial teórico que levantou padrões de qualidade para a EaD. Assim, três documentos consubstanciam essas definições: os padrões internacionais AFT (2000), ODLQC (2016) e o padrão nacional emitido pelo MEC (2007). Então, os níveis intermediários foram definidos como: material impresso, vídeos, programas televisivos e radiofônicos, videoconferências, CD-Rom, páginas $W E B$ e objetos de aprendizagem. 
A terceira e última etapa consistiu na construção da matriz 4x4, que deriva o termo de topo para os níveis intermediários. Nessa etapa se construiu o desenho da pesquisa que foi apresentado aos participantes do estudo, a fim de validar o modelo. Para tanto, primeiramente questionou-se os materiais didáticos citados pelo MEC (2007) são mesmos recursos efetivamente disponibilizados para os alunos de graduação, na sequência apresentou-se os materiais didáticos e os padrões de qualidade elencados pela pesquisa bibliográfica.

Os testes foram realizados ao longo do mês de julho (2016) e os resultados indicaram os materiais mais utilizados: livro texto, vídeo aula, rádio e chat.

Quadro 5. Matriz 4 x 4 Materiais didáticos

\begin{tabular}{|l|c|c|c|c|}
\hline \multicolumn{5}{|c|}{ Termo de Topo: Avaliação de Materiais didáticos para a EAD } \\
\hline & Livro texto & Vídeo Aulas & Chat & Rádio \\
\hline Livro texto & 1 & & & \\
\hline Vídeo Aulas & & 1 & & \\
\hline Chat & & & 1 & \\
\hline Rádio & & & & 1 \\
\hline
\end{tabular}

Fonte: Autores (2016).

Por meio dessa matriz, foram realizadas as comparações, par a par, por grau de prioridade. Na sequência os subitens foram abertos de acordo com os padrões de qualidade emitidos pelo AFT (2000), MEC (2007) e ODLQC (2016).

Quadro 06. Padrões de qualidade

\begin{tabular}{|l|l|}
\hline \multicolumn{1}{|c|}{ Padrão de Qualidade } & \multicolumn{1}{c|}{ Avaliação } \\
\hline AFT (2000); MEC (2007) & Conteúdo abrangente \\
\hline ODLQC (2016) & Material atualizado \\
\hline MEC (2007) & Linguagem dialógica \\
\hline MEC (2007) & Indicação de bibliografia ou materiais complementares \\
\hline ODLQC (2016) & Livre de erros, viés conceituais, ou de abordagem \\
\hline
\end{tabular}

Fonte: Pesquisa bibliográfica (2016).

Após a elaboração do esboço da matriz de 4x4, a partir dos termos de topo e intermediários, esse desenho foi submetido à apreciação dos coordenadores que sugeriram outros itens, os quais deveriam ser avaliados, alguns são comuns a mais de um dos materiais, outros específicos. Essa aplicação ocorreu em agosto de 2016. 
Figura 1. Avaliação dos materiais didáticos

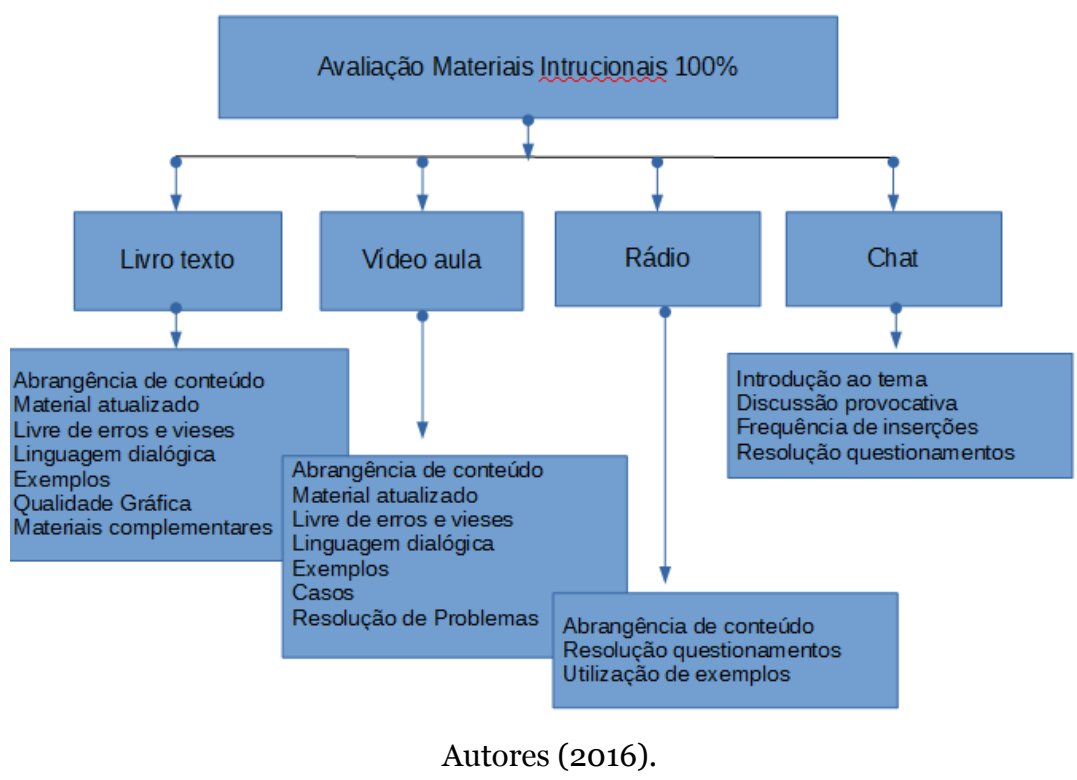

Foram identificados itens comuns, para as sub-categorias, que são características de qualidade para mais de um material: utilização de exemplos que estimulem o raciocínio; apresentação de casos; e resolução de problemas. Itens a serem avaliados especificamente para o chat: introdução ao tema; apresentação em formato de discussão provocativa; frequência de inserções; e resolução de questionamentos específicos. Com isso posto, procedeu-se ao desenho da pesquisa que incluiu as sugestões dos decisores.

Segundo Gomes, Gomes e Almeida (2002) para verificar se a função obtida a partir das respostas é consistente, se realiza um teste, para verificar se os resultados são compatíveis com as preferências dos decisores.

$O$ valor obtido pela comparação par a par dos elementos $i$ com o elemento $j$ formarão a matriz $\mathrm{A}$, onde $\mathrm{A}=\left(\mathrm{a}_{\mathrm{ij}}\right)$, sendo essa uma matriz recíproca tal que $\mathrm{a}_{\mathrm{ji}}=$ $1 / a_{i j}$, se os julgamentos fossem perfeitos. Em todas as comparações seria possível verificar que $\mathrm{a}_{\mathrm{ij}} \mathrm{x}_{\mathrm{jk}}=\mathrm{a}_{\mathrm{ik}}$, para qualquer $i, j, k$, nesse caso a matriz seria considerada consistente. Se os juízos forem consistentes, tem-se: $\lambda \max =n$ e $a_{i j}=w_{i} / w_{j}$, no entanto alguma inconsistência é admitida pelo AHP, essa pode ser medida da seguinte forma: quanto mais próximo estiver o valor de $\lambda$ max de $n$, maior será a consistência dos juízos, portanto, $\lambda \max -n$ é um indicador de consistência (Gomes, Araya e Carignano, 2011). 
Saaty (1991, p. 260) aponta que uma matriz é consistente quando:

$\mathrm{IC}=(\lambda \max -\mathrm{n}) /(\mathrm{n}-1)$

(equação 1)

IC: Índice de Consistência

$\lambda$ max: autovalor de A e w

n: número de elementos

Já a Razão de Consistência (RC) é obtida pela fórmula (SAATY, 1980):

$\mathrm{RC}=\mathrm{IC} / \mathrm{IR}$

RC: Razão de Consistência

IC: Índice de Consistência

IR: Índice Aleatório calculado para matriz quadradas de ordem $n$

(equação 2)

Onde o IC é calculado a partir da fórmula apresentada na equação 1 e o IR, que é um índice aleatório, calculado a partir de matrizes quadradas de ordem $n$ e foi elaborada pelo Laboratório Nacional de Oak Ridge, EUA (Gomes, Araya e Carignano, 2011).

Tabela 2. Valores de IR para matrizes quadradas de ordem $n$

\begin{tabular}{|c|c|c|c|c|c|c|}
\hline $\boldsymbol{n}$ & $\mathbf{2}$ & $\mathbf{3}$ & $\mathbf{4}$ & $\mathbf{5}$ & $\mathbf{6}$ & $\mathbf{7}$ \\
\hline $\boldsymbol{I R}$ & 0,58 & 0,9 & $\mathbf{1 , 1 2}$ & $\mathbf{1 , 2 4}$ & 1,32 & $\mathbf{1 , 4 1}$ \\
\hline
\end{tabular}

Fonte: Gomes, Araya e Carignano (2011, p. 48).

As informações foram registradas no software Assistat 7.7 beta, que geraram as matrizes de preferências e formaram uma relação na sequência por critérios de importância, proporcionando o cálculo dos índices de consistência (IC). Assim, demonstra que os cálculos representam a realidade que se propunham a apresentar e trazem a razão de consistência do modelo (RC). Saaty (1991) infere que alguma inconsistência é admitida e o índice máximo que indica que o modelo apresenta uma realidade é RC 0,10.

O presente estudo primou por investigar o tema junto a coordenadores de curso de graduação em Contabilidade a distância, pelo fato de conhecerem os documentos que embasam a criação das matrizes curriculares, possuírem uma visão geral dos conteúdos que devem ser abordados no decorrer do curso, e serem requisitados a avaliar periodicamente materiais didáticos disponibilizados aos alunos. Observase que o AHP necessita que os respondentes avaliem cada item, de forma direta e recíproca, assim os pesquisadores aplicaram pessoalmente as matrizes de preferência, evitando que houvessem dúvidas sobre a representatividade de cada conteúdo. Assim procedeu-se à escolha de três coordenadores que atuam na EaD. 
Tabela 3. Atores participantes da pesquisa

\begin{tabular}{|l|l|l|}
\hline Instituição & \multicolumn{1}{|c|}{ Estrutura } & \multicolumn{1}{c|}{ Coordenador } \\
\hline A & $\begin{array}{l}\text { Instituição Privada, Conceito } \\
\text { Preliminar de Curso 4. }\end{array}$ & $\begin{array}{l}\text { Atua a mais de } 7 \text { anos como docente e } \\
\text { 3 como coordenador }\end{array}$ \\
\hline \multirow{2}{*}{ B } & $\begin{array}{l}\text { Instituição Privada, Conceito } \\
\text { Preliminar de Curso 5. }\end{array}$ & $\begin{array}{l}\text { Atua mais de 10 anos como docente e } \\
\text { 4 como coordenador }\end{array}$ \\
\hline C & $\begin{array}{l}\text { Instituição Privada, Conceito } \\
\text { Preliminar de Curso 5. }\end{array}$ & $\begin{array}{l}\text { Atua mais de 8 anos como docente e } \\
\text { 5 como coordenador }\end{array}$ \\
\hline
\end{tabular}

Autores (2016).

\section{ANÁLISE DOS RESULTADOS}

Os pesquisadores apresentaram o método e o desenho da pesquisa para os respondentes e os dados foram inseridos no software Assistat 7.7 Beta.

Cada constructo identificado como de primeira ordem: livro texto, vídeo aulas, chat e rádio, foi avaliado reciprocamente em sua matriz 4x4, bem como, a própria matriz gerou seu índices de consistência (IC) e razão de consistência do modelo (CR). A figura 2 apresenta o desenho do estudo a partir do termo de topo, Avaliação dos Materiais didáticos, que representa 100\% do estudo, e que obteve um IC e RC de o,03. Saaty (1991) afirma que de forma geral, se o IC for menor do que 0,10 o modelo atende uma medida de consistência de forma satisfatória.

Figura 2. Dimensões da avaliação da qualidade do e-learning

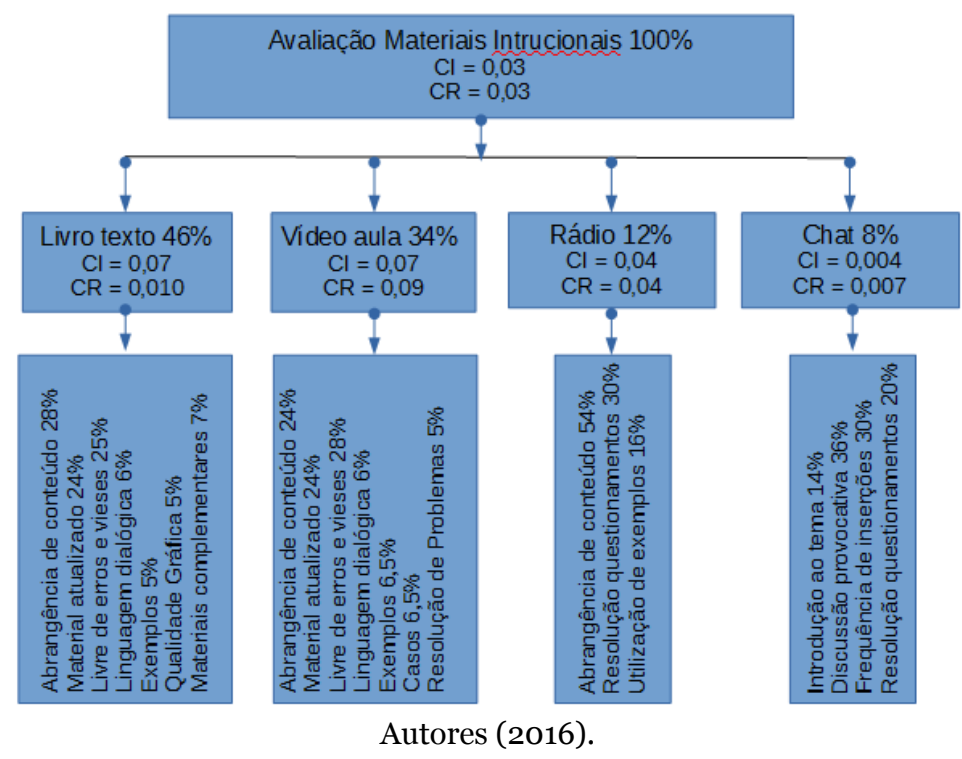


A partir do termo de topo e com base nos referenciais de qualidade que contemplam os materiais didáticos, AFT (2000), MEC (2007) e ODLQC (2016), foram derivados os termos intermediários e categorias. Os respondentes forneceram um modelo de decisão, onde, no processo de avaliação de materiais didáticos, o livro texto é considerado o material mais importante $46 \%$, na sequência os vídeos aulas são classificadas em 34\%, o chat detém $12 \%$ e o rádio com $8 \%$. Assim, os esforços no monitoramento da qualidade, ao que diz respeito ao material instrucional, devem se concentrar no livro texto seguido da vídeo aula.

Quadro 7. Avaliação de Qualidade de Materiais Didáticos na EaD

\section{Termo de Topo: Avaliação de Qualidade dos Materiais Didáticos na EaD}

\section{Constructos}

CI 0,03

CR 0,03

\begin{tabular}{|c|c|c|c|}
\hline \multirow{7}{*}{$\begin{array}{l}\text { Livro texto } \\
\text { Importância do } \\
\text { Indicador } 46 \% \\
\text { CI o,o7 } \\
\text { CR o,10 }\end{array}$} & Abrangência de Conteúdo & $28 \%$ & $13 \%$ \\
\hline & Material atualizado & $24 \%$ & $11 \%$ \\
\hline & $\begin{array}{l}\text { Livre de erros, viés conceituais, ou de } \\
\text { abordagem }\end{array}$ & $25 \%$ & $12 \%$ \\
\hline & Linguagem dialógica & $6 \%$ & $3 \%$ \\
\hline & Utilização de exemplos & $5 \%$ & $2 \%$ \\
\hline & Qualidade gráfica & $5 \%$ & $2 \%$ \\
\hline & $\begin{array}{l}\text { Indicação de bibliografia ou materiais } \\
\text { complementares }\end{array}$ & $7 \%$ & $3 \%$ \\
\hline \multirow{7}{*}{$\begin{array}{l}\text { Vídeo aulas } \\
\text { Importância do } \\
\text { Indicador } 34 \% \\
\text { CI o,o7 } \\
\text { CR o,o9 }\end{array}$} & Abrangência de Conteúdo & $24 \%$ & $8 \%$ \\
\hline & Apresenta atualizações & $24 \%$ & $8 \%$ \\
\hline & $\begin{array}{l}\text { Livre de erros, viés conceituais, ou de } \\
\text { abordagem }\end{array}$ & $28 \%$ & $10 \%$ \\
\hline & Linguagem dialógica & $6 \%$ & $2 \%$ \\
\hline & $\begin{array}{l}\text { Utilização de exemplos que estimulem o } \\
\text { raciocínio }\end{array}$ & $6,5 \%$ & $2 \%$ \\
\hline & Apresentação de Casos & $6,5 \%$ & $2 \%$ \\
\hline & Resolução de problemas & $5 \%$ & $2 \%$ \\
\hline \multirow{4}{*}{$\begin{array}{l}\text { Chat } \\
\text { Importância do } \\
\text { Indicador 12\% } \\
\text { CI o,04 } \\
\text { CR o,o4 }\end{array}$} & Introdução ao tema & $14 \%$ & $2 \%$ \\
\hline & $\begin{array}{l}\text { Apresentação em formato de discussão } \\
\text { provocativa }\end{array}$ & $36 \%$ & $4 \%$ \\
\hline & Frequência de inserções & $30 \%$ & $4 \%$ \\
\hline & Resolução de questionamentos & $20 \%$ & $2 \%$ \\
\hline
\end{tabular}




\begin{tabular}{|c|c|c|c|}
\hline \multicolumn{4}{|c|}{ Termo de Topo: Avaliação de Qualidade dos Materiais Didáticos na EaD } \\
\hline $\begin{array}{c}\text { Constructos } \\
\text { CI } 0,03 \\
\text { CR } 0,03\end{array}$ & Categorias & $\begin{array}{l}\text { Importância } \\
\text { do Indicador }\end{array}$ & $\begin{array}{l}\text { Avaliação do } \\
\text { Indicador }\end{array}$ \\
\hline \multirow{3}{*}{$\begin{array}{l}\text { Rádio } \\
\text { Importância do } \\
\text { Indicador 8\% } \\
\text { CI o,o04 } \\
\text { CR o,oo7 }\end{array}$} & Abrangência de Conteúdo & $54 \%$ & $4 \%$ \\
\hline & Resolução de questionamentos & $30 \%$ & $2 \%$ \\
\hline & Utilização de exemplos & $16 \%$ & $1 \%$ \\
\hline
\end{tabular}

Autores (2016).

O quadro 7 agrupa os itens analisados, em conjunto com o CI e CR e traz uma avaliação do indicador, calculada a partir da importância do indicador da categoria em relação ao constructo. Essa medida aponta a representatividade do item em relação ao seu constructo.

Considerando todas as categorias avaliadas, o item livro texto é o que mais requer requisitos de qualidade. A abrangência de conteúdo é a que mais necessita atenção, com avaliação de $13 \%$, seguida de $12 \%$ para conteúdos livre de erros, viés conceituais, ou de abordagem e $11 \%$ para o material atualizado. No item vídeo aulas, a importância do material ser livre de erros, viés conceituais, ou de abordagem computou $10 \%$. Ressalta-se que esses foram elencados como referenciais de qualidade, tanto para a AFT (2000), quanto para o MEC (2007).

De posse da observação desse processo analítico hierárquico, os gestores de cursos na modalidade EaD podem direcionar seus esforços para os itens de maior representatividade, dentro dos constructos considerados padrões de qualidade para os materiais didáticos. Portanto, deve-se considerar a importância dos docentes na modalidade EaD, pois os mesmos organizam o livro texto e são responsáveis pela elaboração da vídeo aula.

\section{CONSIDERAÇÕES FINAIS}

Após a busca nas bases de dados Ebsco Host e Capes, não foram encontrados referenciais que fornecessem um padrão de qualidade para os materiais didáticos direcionados a EaD. Os normativos AFT (2000), MEC (2007) e ODLQC (2016), não elegem um grau de importância para cada material instrucional. Assim, a matriz AHP forneceu um modelo de avaliação da qualidade para coordenadores e gestores de cursos à distância utilizarem na avaliação dos materiais didáticos dirigidos aos discentes.

O modelo de avaliação de qualidade deve priorizar os materiais: livro texto, em termos de abrangência de conteúdos direcionados à temática, ser livre de erros, viés conceituais ou de abordagem e estar atualizado em termos de legislação, conteúdos e temas. Para as vídeo aulas, o padrão de qualidade (como no modelo de avaliação 
de qualidade) deve contemplar uma exposição livre de erros, viés conceituais ou de abordagem, devendo ser atualizada perante conteúdos e normas, e abrangente em termos do conteúdo contemplado na ementa da disciplina. Os itens do material priorizado no resultado da pesquisa mostram a importância do docente na EaD, já que normalmente são os responsáveis pelas vídeo aulas e muitas vezes elaboram o livro texto, disponibilizados aos discentes.

O padrão de qualidade do chat, exige atenção para a inserção da discussão de forma provocativa, uma regularidade na frequência de interações, se tornando um espaço para resolução de questões ou dúvidas dos alunos. É um momento de interação, mesmo que assíncrono. A qualidade do rádio se concentra em abordar o conteúdo da disciplina de forma abrangente e também é um canal de esclarecimento de supostos questionamentos.

O modelo apresentado contempla graus de importância específicos para cada categoria de qualidade, possibilitando aos gestores de curso medir a qualidade de seus materiais didáticos, nesse sentido a preocupação para com a qualidade dos materiais didáticos deve recair sobre o livro texto e vídeo aulas. Para tanto, recomenda-se para estudos futuros aplicar o modelo de avaliação de qualidade em uma instituição de $\mathrm{EaD}$, a fim de avaliar as diferenças geradas entre a realidade observada e o padrão de qualidade estabelecido pelo modelo.

\section{REFERÊNCIAS BIBLIOGRÁFICAS}

AFT. (2000) American Federation of Teachers. Recuperado de http://www.aft. org

Almeida, M. E. B. (2012). Formação de educadores a distância na pós-graduação: potencialidades para o desenvolvimento da investigação e produção de conhecimento. Educação \& Sociedade, 33, 1053-1072.

Almeida, M. E. B. (2013). O computador portátil e a inovação educativa: das intenções à realidade. Em M. Bianconcini, P. Dias y B. Duarte, Cenários de inovação para a educação na sociedade digital, (21-46). São Paulo: Loyola.

Almeida, A. T. (2013). Processo de decisão nas organizações: construindo modelos de decisão multicritério. São Paulo: Atlas.

Argüelles, M. J. M., Callejo, M. B., e Farrero, J. M. C. (2013). Les dimensions de la qualitat del servei percebuda en entorns virtuals de formació superior. RUSC.
Universities and Knowledge Society Journal, 10(1), 89-106.

Associação Brasileira de Educação a Distância (ABED). (2016). Informações sobre o Ensino a Distância. Recuperado de http://www.abed.org.br/site/pt/ universo ead/catalogo de cursos

Brasil. Leis e Diretrizes e Bases da Educação Nacional. Decreto n. 5.622, de 19 de dezembro de 2005. Regulamenta o art. 80 da Lei 9.394/96, 20 dez. 1996. Estabelece as diretrizes e bases da educação nacional. Diário Oficial da União, Brasília, ano 134 , n. 248, pp. 27833-27841, dez. 2005. Recuperado de http://portal.mec.gov.br seed/arquivos/pdf/dec 5622.pdf

Brasil. Lei $\mathrm{n}^{0}$ 9.131, de 20 de dezembro de 1995. Criou o Conselho Nacional e o ENC. Recuperado de http://wwwt.senado.gov. br/legbras

Caetano, C. C. R., de Oliveira Cardoso, T. A., Miranda, G. J., e Calheira de Freitas, 
S. (2015). Desempenho no Enade em Ciências Contábeis: Ensino a Distância (EaD) Versus Presencial. Revista Universo Contábil, 11(4), 147.

Downes, S. (2009). Learning networks and connective knowledge. Instructional Technology Forum. Em J. C. Mota, Da Web 2.o ao e-Learning 2.o: Aprender na rede. Dissertação de mestrado em Ciências da Educação, especialidade Pedagogia do e-Learning, Universidade Aberta, Portugal.

Fratucci, MVB. (2015). Ensino a distância comoestratégicadeeducaçãopermanente em saúde: impacto da capacitação da equipe de estratégia de saúde da família na organização dos serviços. Tese de doutorado apresentado a Faculdade de Odontologia da Universidade de São Paulo para obtenção do título de doutor em Ciências Odontológicas.

García Aretio, L. (2016). Los inicios históricos de una completa universidade pública a distância: lá UNED de España. RIED. Revista Iberoamericana de Educación a Distancia, 19(1), 9-21.

Gil, A. C. (2012). Didática do Ensino Superior. São Paulo: Atlas.

Gomes, L. F. (2013). EAD no Brasil: perspectivas e desafios. Avaliação, 18(1), 13-22.

Gomes, L. F. A. M., Gomes, C. F. S., e Almeida, A. T. (2002). Tomada de decisão gerencial: enfoque multicritério. São Paulo: Atlas.

Gomes, L. F. A. M., Gonzales-Araya, M. C., e Carignano, C. (2004). Tomada de Decisões em Cenários Complexos. Rio de Janeiro: Pioneira Thompson Learning.

Kneller, G. (1980). A ciência como atividade humana. Rio de Janeiro: Zahar.

Komarinski, C. A. A. (2015). Comparison of Student Achievement on the National ServSafe Examination in an Online Versus a Traditional Classroom Format. Doctoral dissertation, Robert Morris University. Pittsburgh, USA, ProQuest
Dissertations and Teses database. (UMI No. 3708236).

MEC/SEED (2007). Referenciais de Qualidade para Educação Superior. Recuperado de http://portal.mec.gov.br/ seed/arquivos/pdf/legislacao/refead1.pdf

Montalvo, E., Luna, D., e Montenegro, E. (2010). La evolución y adopción de estándares en la formación virtual. Recuperado de http://docplaver. es/1140435-La-evolucion-y-adopcionde-estandares-en-la-formacion-virtualelena-campo-montalvo-daniel-meziatLuna-elena-campo-daniel-meziat-uah. html

Mugnol, M. (2009). A educação a distância no Brasil: conceitos e fundamentos. Rev. Diálogo Educ., Curitiba, 9(27), 335-349.

ODLQC (2005), Standards in Open and Distance Learning. Recuperado de http://www.odlqc.org.uk/assess-guide/ standards

Oliveira, V. D., y Martins, C. H. (2015). AHP: ferramenta multicritério para tomada de decisão shopping centers. Curitiba: Appris.

Paese, C. R. (2012). Educação a distância (EaD) e o uso das tecnologias de informação e comunicação (tics), baseada em ambientes virtuais de aprendizagem (ava): algumas reflexões sobre a importância da tutoria on-line. Revista Eletrônica do Curso de Pedagogia da UFG, campus de Jatai.

Peeva, K. (2010). Theoretical aspects of the assessment of quality in higher education. Trakia Journal of Sciences, 8(2), 429435.

Pérez, M. G., y García Aretio, L. (2016). Líneas de investigación y tendencias de la educación A distancia en américa latina a través de las tesis Doctorales. RIED Revista Iberoamericana de Educación a Distancia, 17(1), 201-230.

Ramírez, J. Z. (2016). Prediction factors of student satisfaction in online Courses, RIED. Revista Iberoamericana de 
Educación a Distancia, 19(2), 217235. doi: http://dx.doi.org/10.5944/ ried.19.2.15112

Rué, J., Amador i Guillem, M., Gené, J., e Rambla, F. X. (2009). Evaluar la calidad del aprendizaje en educación superior: el modelo ECAo8 como base para el análisis de evidencias sobre la calidad de la E-A en E. Superior. REDU, Revista de Docencia Universitaria, 7(2), 1-22.

Saaty, T. L. (1991). The Analytic Hierarchy Process. Planning, priority, setting, resource allocation. São Paulo: Makron Books McGraw-Hill.

Saaty, T. L. (2008). Decision making with the analytic hierarchy process. International Journal of Services Sciences, 1(1), 83-98.

Silva, M. P. D., Melo, M. C. de O. L., e Muylder, C. F. DE. (2015). Educação a distância em foco: um estudo sobre a produção científica brasileira. $R A M, R E V$. ADM. Mackenzie, 16(4). São Paulo, SP. doi: http://dx.doi.org/10.1590/1678 69712015/administracao.v16n4p202-230

Tachizawa, T., e Andrade, R. O. B. (2003). De Tecnologias da informação aplicadas às instituições de ensino e às universidades corporativas. São Paulo: Atlas.
Terçariol, A. A. de L. et al. (2016). As dimensões da avaliação em cursos online: reflexões e importância. RIED. Revista Iberoamericana de Educación a Distancia, 19(2), 283-300 doi: http:/ dx.doi.org/10.5944/ried.19.2.14753

Tondin, J. E. M. (2009). Prospeccção de implementação de educação à distância para a disciplina de fundamentos de física nuclear na Pós-Graduação do Ipen utilizando infra - estrutura de software livre. Dissertação de Mestrado, Instituto de Pesquisas Energéticas e Nucleares, Universidade de São Paulo, São Paulo.

Udo, G. J., Bagchi, K. K., e Kirs P. J. (2011). Using SERVQUAL to assess the quality of e-learning experience. Computers in Human Behavior, 27(3), 1272-1283.

Valente, C., e Mattar, J. (2007). Second Life e Web 2.o na Educação: o potencial revolucionário das novas tecnologias. São Paulo: Novatec.

Vagarinho, J. P., e Lamas-Nistal, M. (2013). Evaluación de la calidad de los procesos del e-learning: Una propuesta con nuevas dimensiones. Teoría de la Educación; Educación y Cultura en la Sociedad de la Información, 14(2), 473.

\section{PERFIL ACADÊMICO E PROFISSIONAL DOS AUTORES}

Silvio Paula Ribeiro. Bacharel em Ciências Contábeis pela Fundação Educacional de Votuporanga - FEV (1994), Mestre em Engrenharia da Produção UNIMEP (1995), Doutorando em Contabilidade pela Universidade do Vale do Rio dos Sinos - UNISINOS, professor na Universidade Federal de Mato Grosso do Sul - UFMS, Campus de Três Lagoas. Tem interesse em pesquisar os temas ensino de contabilidade e informacões para usuários externos.

E-mail: spribeiro@hotmail.com

Viviane da Costa Freitag. Técnica em Contabilidade pelo Colégio Estadual Santo Agostinho - CESA (1992), Bacharel em Ciências Contábeis pela Universidade Estadual do Oeste do Paraná - UNIOESTE (2004), Mestre em Contabilidade pela Universidade Federal do Paraná - UFPR (2008) e Doutoranda em Contabilidade pela Universidade do Vale do Rio dos Sinos - UNISINOS, professora de cursos de graduação e especialização, nas modalidades presencial e à distância. Tem como 
interesses de pesquisa: o ensino de contabilidade e temas voltados ao controle e gestão nas organizações.

E-mail: vivifreitag@gmail.com

Miguel AfonsoSellitto. Graduado em Engenharia Eletrônica pela Universidade Federal do Rio Grande do Sul (UFRGS, 1978), especialista em Administração pela UNISINOS (1997), mestre e doutor em Engenharia de Produção pela UFRGS (1999 e 2005). Professor Titular da Universidade do Vale do Rio dos Sinos (UNISINOS). Tem como interesses de pesquisa: Logística e Gestão da Cadeia de Suprimentos, Gestão verde da Cadeia de Suprimentos, Sustentabilidade Organizacional, Estratégia de Produção, Complexidade, Medição de Desempenho e Gestão da Manutenção Industrial e Assistência Técnica.

E-mail: sellitto@unisinos.br

\section{ENDEREÇO DOS AUTORES}

UNISINOS -Av. Unisinos, 950.

Bairro Cristo Rei, São Leopoldo

RS CEP: 93.022- 750 .

Data de recebimento do artigo: 14/09/2016

Data de aceite do artigo: 02/12/2016

\section{Como citar este artigo:}

Ribeiro, S. P., da Costa, V., e Sellitto, M. A. (2018). Instrumento de mensuração de qualidade de materiais didáticos para a educação à distância. RIED. Revista Iberoamericana de Educación a Distancia, 21(1), pp. 239-259. doi: http://dx.doi. org/10.5944/ried.21.1.17157 